\title{
Development and Role of Electronic Library in Information Technology Teaching in Bulgarian Schools*
}

\author{
Tsvetanka Georgieva-Trifonova \\ Department of Mathematics and Informatics \\ University of Veliko Tarnovo \\ Veliko Tarnovo, Bulgaria
}

\author{
Gabriela Chotova \\ Professional School of Electrical and Electronics \\ Gorna Oryahovitsa \\ Bulgaria
}

\begin{abstract}
The electronic library can be considered as an interactive information space. Its creation substantially supports the communication between the teachers and the student, as well as between the teachers and the parents. The enlargement of information space allows improving the efficiency and the quality of teaching, assigning more projects for realization.
\end{abstract}

The main purpose of this paper is to examine the role of the electronic library in teaching of information technologies in Bulgarian schools for providing more time for applying the learned material in order to increase the effectiveness of the educational process. We summarize and represent the advantages and disadvantages of the use of digital libraries in teaching information technologies together with the main features of a developed electronic library for teaching and educational subsidiary materials.

Keywords-electronic library; information technology teaching; multimedia information system

\section{INTRODUCTION}

In recent years, there is in particular a lot of talk about how interactive teaching methods of the education help to students' motivation. Today students, and not only them, are in direct access to digital technologies in every aspect of their lives. It is clear that this has a huge impact on the personality of the student, his or her behavior and way of thinking. As to the educational system, developing of the new technologies passes with a speed higher than "escaping of the students from the lessons" and provide many more opportunities at the same time - many more challenges to the abilities of the teachers.

The modern innovative pedagogical technologies implement new training model based on complex information interactions between teachers, students and the means of information and communication technologies. Electronic technologies are implicated throughout the learning process during the preparation and presentation of some information. The teacher remains to be a leading figure in structuring and preparing of the educational content. The main purpose of this paper is to examine the role of the electronic library in teaching information technologies in order to provide more time for the implementation of the material being learnt, and to increase the effectiveness of the educational process.

*The research is financed by project №09-590-13/10.04.2013, Integrated electronic services for the citizens and the business of St.Ciryl and St.Methodius University of Veliko Turnovo.
In the following sections, the advantages and disadvantages of the use of digital libraries in teaching information technologies are summarized and there are presented the main features of developed electronic library for teaching and educational subsidiary materials.

\section{THE ROLE OF ELECTRONIC LIBRARY IN TEACHING INFORMATION TECHNOLOGIES}

This study is motivated by observations and experience of one of the authors as a teacher of informatics, information technologies and vocational subjects in secondary school. These items are under specialty "System Programming", profession "Programmer". The authors of this paper notice some certain characteristics, related to school work and summarize them as follows:

- Too many hours are set aside to receive theoretical knowledge than for their consolidation with the help of their practical application;

- Lessons for acquiring practical skills are much less compared to those for obtaining of theoretical knowledge;

- As a result, the teacher is not always able to ensure consideration of all problems of a topic or a task.

These conclusions are the main motivation for the development of a web-based multimedia information system, which should serve as an electronic library for teaching and educational subsidiary materials. The main purpose of the proposed system is to allow input, storage, search and retrieval of the materials related to the themes of the specific subjects. In this way the students more easily can find the relevant information of a topic for a particular class. They have access to the materials in class, allowing more time for discussion on the topic. In parallel with the observation of the topic, there can be discussed concrete examples and to solve various tasks. As a result, more time for acquisition of the practical skills and skills for teamwork is provided.

The main purpose of the use of virtual environment for representing the teaching materials is to support the traditional forms of training. Its achievement sets the following requirements, which the development of an electronic library of teaching and educational subsidiary materials has to meet: 
- Developing a multimedia information system that serves as an electronic library of educational and educational subsidiary materials;

The electronic library can be seen as a kind of multimedia system for retrieving information (multimedia information retrieval system) [1].

- The users (students) should have free access to the materials, without registration;

- Providing an access to teaching and educational subsidiary materials such as:

○ Homework - assignments and their solutions;

○ Example of variants of tests;

○ Projects - developments of students;

- Thesis of students;

- Lessons containing information that complements the mandatory educational content;

o Other materials.

- Providing an opportunity for input and storage to:

○ Title, authors, type, description (abstract), keywords;

○ Documents (.doc, .pdf), presentations (.ppt, .pdf), images, audio, video, databases, programs of the studied programming languages, etc.

- Being able to perform searching for materials by:

○ Title, authors, type, description (abstract), keywords.

III. ADVANTAGES AND DISADVANTAGES OF THE USE OF ELECTRONIC LIBRARY IN TEACHING INFORMATION TECHNOLOGIES

The main advantages of using an electronic library in teaching information technologies, which can be mentioned, are:

- The users (students) have access to pre-prepared training material at a time, convenient for them;

The system allows students to use it at a time, convenient for them. Moreover, the students can view and absorb the information in a manner and at a speed of their own pace and to communicate with the teacher.

- There is a free eligibility of training modules;

- There is given a fast and easy access to materials containing theoretical presentation of a topic, as well as the materials, presented practical implementation of the issues, being observed;

- The teacher has more time for practical training;

Materials stored into the multimedia information system, help or replace part of theoretical training;
- Multimedia information system helps to organize and conduct training sessions more dynamic;

- There is additional motivation of students for better and more completed presentation of their workings out;

- It helps to increase the interest and involvement of the students;

- It involves the skills of students to work in a team;

- There is an emphasis on the activities of the students;

- The teacher is a mentor;

- Training materials, available through the system, cover all subjects being taught.

- We have also noticed the following disadvantages:

- It requires an access to a computer and Internet;

- A secure connection is necessary;

- The connection is no always fast enough;

- It requires time and effort to develop and maintain the electronic library.

\section{REVIEW OF EXISTING ELECTRONIC LIBRARIES FOR}

TEACHING AND EDUCATIONAL SUBSIDIARY MATERIALS

We conduct a research of the existing web-based systems that provide access to teaching and educational subsidiary materials and are supported by teachers in Bulgarian schools. Their options are briefly presented below:

- Electronic teaching materials of the Technological School "Electronic Systems" at the Technical University, Sofia city [2];

This website is managed by teachers and offers access to lectures and other materials of software specialties in Technological School "Electronic Systems". The proposed materials are designed to help to train students in subjects: Modular Java (Java and OSGI); Object-oriented programming (C ++); Python/Introduction to Programming; Software; Robotics; Database management system; Programming technology; Operating systems; Internet programming, etc. There are given assignments for thesis and requirements to them. There is not access available to developments of the students - assignments or thesis. This site is managed by Wordpress.

- Electronic library of the High School "Raycho Karolev", Gabrovo town [3];

The electronic library contains electronic tutorials, presentations and training projects concerning subjects of natural sciences and humanities cycle, as well as those of the initial stage of the primary education. The website implementation is based on PHP, there are created separated pages for each class, which lists topics for different subjects and materials for them. Besides lessons, there are offered tasks for exercises, assignments for projects, but there is a lack of their solutions and developments. It is impossible to carry out any searching. 
- Electronic teaching materials of Musa Musa, a teacher of informatics and information technologies at the High School "Priest Paisii", Kardzhali town [4];

The website is implemented by using PHP and represents the distribution of lessons (presentations (.ppt) and additional materials (.rar)) on the subjects: Information Technologies; Informatics; Computer networks; Photoshop; Corel Draw; Web design; $\mathrm{C}$ \#; $\mathrm{C}++$ and others. The access to them is free and also contains a test system. The website does not provide the ability to search and does not offer projects developed by the students.

The author of the website has used the following software tools: HTML, CSS and PHP for the test system, as well as animated gif files.

- Electronic teaching materials of the High School "Nayden Gerov", Lom city [5];

The website contains lessons and tasks for $\mathrm{C}++$ and Pascal. It is created for publishing tasks and their solutions. In order to publish the solutions of the tasks, the students must register themselves. Solutions are visible for everybody after an approval. The website provides the ability to search, but the result is only concerning the tasks for exercise. Lessons are not included into the search. This website is managed by Wordpress.

- Electronic teaching materials of the High School "Dimitar Blagoev", Provadia town [6];

The website is created to help to the students in their training in informatics and information technologies. It contains a variety of materials, divided into classes. Much of the materials except in HTML format are published in pdf format. Only after registration the user has access to the sections "Informatics - Other", "IT - Others", "Other subjects" and "Projects of the students", as well as the ability to write comments to some articles. This website allows users to search by keywords in HTML documents.

- Electronic teaching materials on informatics and computer architectures by Dian Pechenyashki - teacher of informatics in the High School of Economics, Veliko Tarnovo town [7];

The website is designed to assist the preparation and selftraining of all students, studying informatics and computer architectures, in upper secondary education. For some lessons in the "Tests" chapter, there have been developed tests on subjects. The website does not provide the ability to search and does not offer students' projects. It is implemented by means of HTML, CSS.

- Electronic teaching materials, related to informatics and information technologies by Diana Martynova - a teacher at the Language School "Prof. Dr. Assen Zlatarov", Veliko Tarnovo town [8];

This website contains materials on informatics, information technologies, computer graphics and computer animation. For each subject, except the particular lesson, there are also exercises and tests.
The website does not provide the ability to search and does not offer projects developed by the students. It is implemented by using the platform alle.bg.

- Electronic teaching materials on informatics and information technologies by Mariana Bankova - a teacher at the Professional High School of Electrical Engineering, Varna town [9];

The website contains materials on informatics, programming, programming part I, programming part II, and information technologies. To each section of the subject there is homework. The website does not provide the ability to search, does not offer development of students. This website is made using a Website Builder, available from http://www.ucoz.com.

- Electronic teaching materials on informatics and information technologies by Zhivka Zhekova - a teacher at the High School with teaching foreign languages "A. S. Pushkin", Varna town [10].

The website contains materials on informatics, information technologies and web design. The website does not provide the ability to search and does not offer students' projects. It is implemented as a static HTML page that provides access to presentations of lessons.

After researching of the current state of the implementation of web-based multimedia information systems for e-learning materials and their use by students, it can be concluded that there is an increasing of their applying in the learning process. The analysis shows the possibilities for development and improvement of the existing systems, which would help to maximize the benefits of their applying.

\section{DEVELOPMENT OF AN ELECTRONIC LIBRARY FOR \\ TEACHING AND EDUCATIONAL SUBSIDIARY MATERIALS}

An electronic library for teaching and educational subsidiary materials in information technologies for secondary school is developed. It contains all the content, taught by one of the author' disciplines. It is available at: http://eclassroom.site88.net.

In Figure 1, we present UML diagram for the specific library. The main participants are the teacher and the students. The interface proposes the following functions:

- Free browsing and viewing the materials by subjects;

- Unlimited accessing to the materials;

- Searching for materials;

- Downloading the materials;

- Log into the system only allowed for the teacher;

- Adding data material is carried out only by the teacher;

- Adding a file only by the teacher;

- Feedback. 


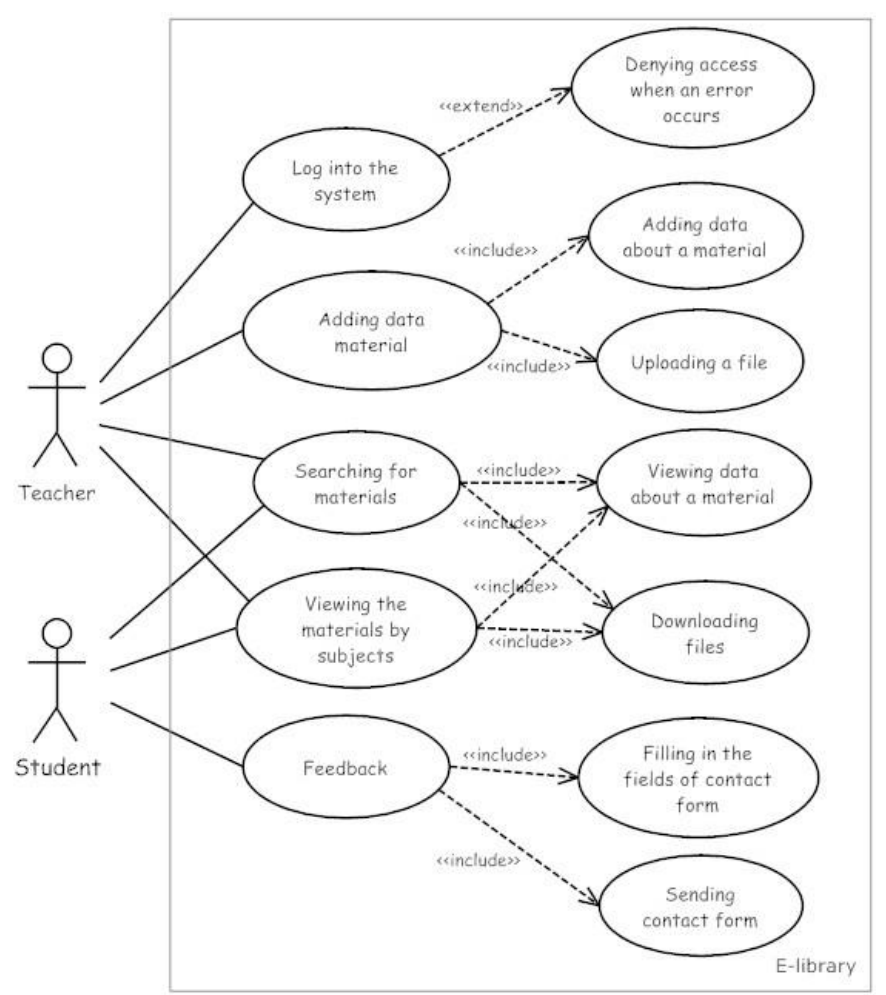

Fig. 1. Interface with UML diagram

We have designed and implemented a relational database $[11,12]$ in order to store the necessary data (materials, authors, subjects, keywords, categories of material, files for viewing and downloading).

\section{A. Data modeling}

In this section, the methodology of the designing the database ELibraryDB, storing the information about the materials, is represented. The main stages of the process of designing the database are $[11,13]$ :

- conceptual designing the database - creation of the conceptual data model which is completely independent from the details related to the implementation;

- logical designing the database - transformation of the conceptual model into the logical model;

- physical designing the database - implementation of the database with the means of a chosen database management system.

1) Conceptual designing

For the conceptual design of the database ELibraryDB we utilize the entity-relationship model, introduced in [14]. The following entity sets are established:

- Materials;

This entity set possesses two attributes: the identifier MaterialID, the material's title - Title.

- KeyWords;
With the entity set KeyWords the following attributes are assigned: the identifier - KeyWordID, the keyword - KeyWord.

- Authors;

The attributes of this entity set are: the identifier AuthorID, the author's name - AuthorName, the author's post - Title.

- Subjects;

With the entity set Subjects the following attributes are assigned: the identifier - SubjectID, the subject's name SubjectName.

- MaterialCategories - the category of the material;

The attributes of this entity set are: the identifier MaterialCategoryID, the category's name - MaterialCategory.

- MaterialFiles - the files for materials;

This entity set possesses two attributes: the identifier FileID, the file location - FilePath.

- FileCategories - the categories of files for materials;

With this entity set the following attributes are assigned: the identifier - FileCategoryID, the file category's name (e.g. document, presentation, image, audio, video) - FileCategory.

- Users.

The attributes of this entity set are: the identifier - UserID, the user's name-Username, the user's password - Password.

The following relationships are defined:

- $A \_M-$ joins entities from the set Authors with entities from Materials and represents the authors of the materials;

- $M \_K-$ joins entities from the set KeyWords with entities from Materials and describes the keywords of the materials;

- $M \_S$ - joins entities from the sets Materials and Subjects and represents the subjects of the materials;

- $M \_M S$ - joins entities from the sets Materials and MaterialCategories and represents the category of the materials;

- $M \_M$ - joins entities from the sets Materials and MaterialFiles and represents the location of the materials;

- $\quad F \_M F-$ joins entities from the sets FileCategories and MaterialFiles and shows the categories of the materials' files;

- $A \_U-$ joins entities from the sets Authors and Users and describes the user names of the materials' authors.

The entity-relationship diagram of the database ELibraryDB is shown in Figure 2. The entity sets are depicted as the rectangles, their attributes - as ellipses, the relationships - as rhombs. 


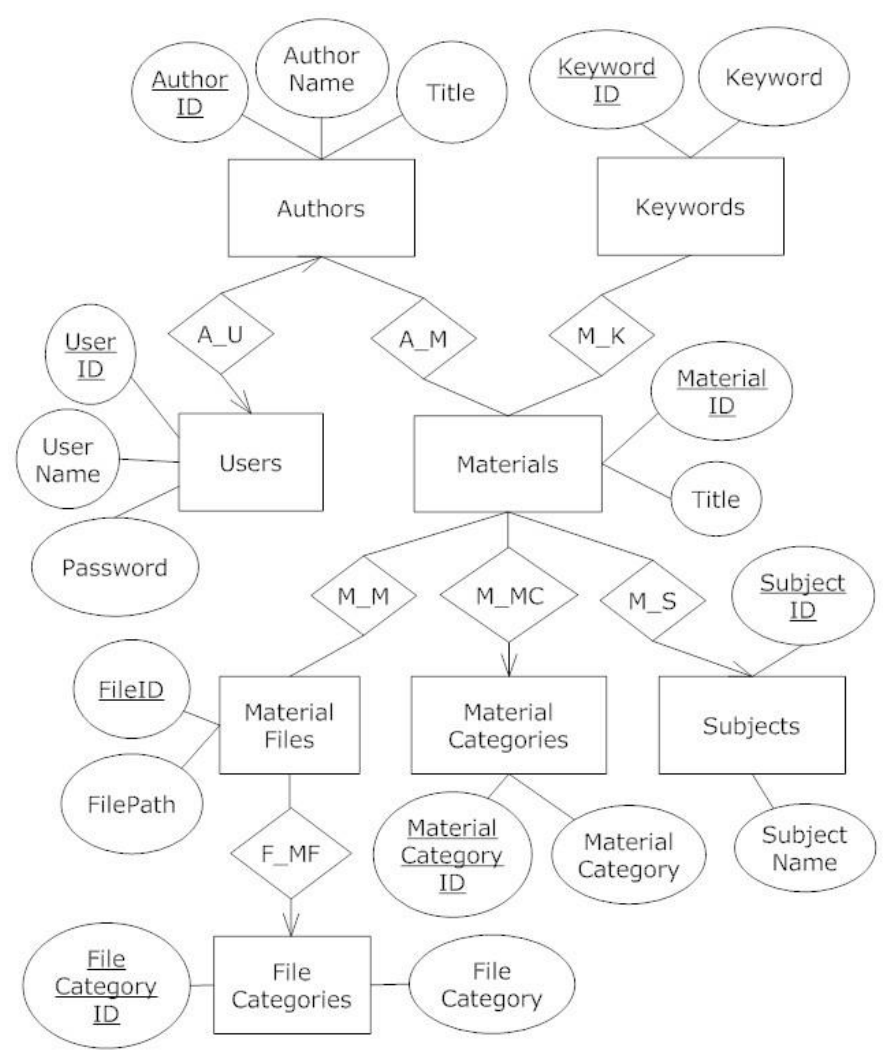

Fig. 2. ER diagram of the database ElibraryDB

\section{2) Logical designing}

The relation tables obtained after the transformation of the entity-relationships diagram into the relational model are presented in Figure 3.

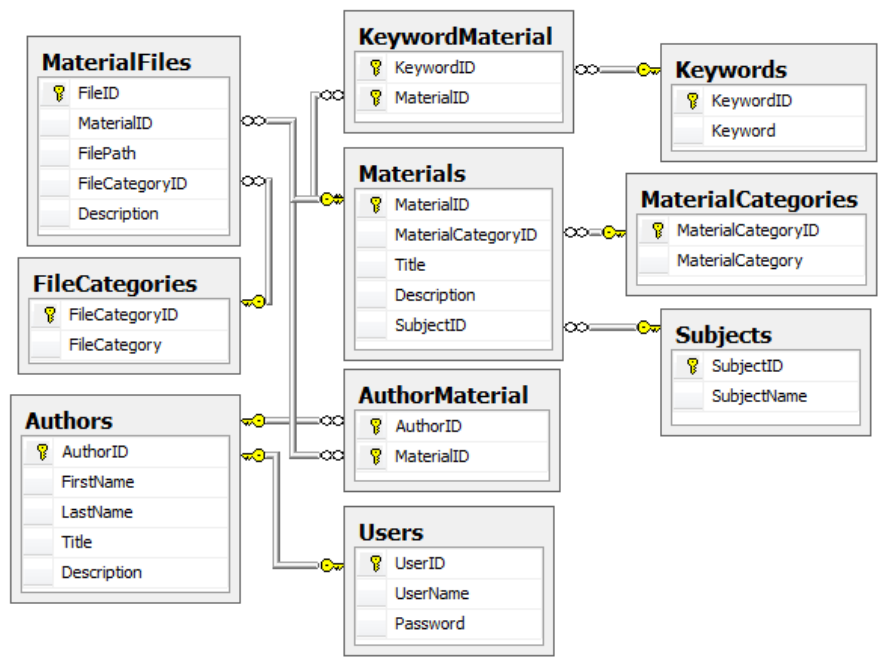

Fig. 3. Relational model of the database ElibraryDB

The proposed relational model allows a future development of the database - creation of new tables and/or attributes for storing additional information.

\section{3) Physical designing}

The database is implemented by means of the database management system MySQL. The structure of the database is defined to provide the best efficiency of the most frequently used operations - insertion, updating, data searching.

\section{B. Description of the electronic library}

The interface for the end user of the multimedia information system is implemented by means of HTML, CSS, PHP and offers the following features:

- Searching into all text attributes - title, author's name, type, description (summary) keywords;

When specifying a particular word (a symbol string) by the user, the found data are visualized and displayed, by using hyperlink to all materials that meet the specified word. Passed string is searched as a substring in the specified text attributes, describing the material.

- A feedback form is implemented;

- Data entry by the system administrator.

For this purpose, a login form is created. When a user enters the username and the password correctly, a new page for input the data for a material opens.

The multimedia information system is under development and has a certain level of completion. The future work includes:

- Advanced searching to set different criteria for different attributes, characterizing materials;

- Opportunity for online viewing (or listening) video (or audio) files tutorials, presentations of works by students, etc.

The proposed system and all materials accessible through it, are intended primarily for students in Bulgarian secondary schools. Therefore, the interface and the materials themselves are in Bulgarian.

\section{CONCLUSION}

The proposed electronic library aims to visualize the teamwork between the students and the teacher leadership skills - to be able to organize and motivate students. Nowadays, the teacher should to stimulate and motivate [15], he or she should be a mentor, he or she should be able to organize different games to exercises students, to get the best results out of them. The teacher has to teach them to present their work and to develop their social skills. At school strength is that the students are all together, they can work in a team, the teacher is there to give them aguidance.

The data storage for the materials in the database provides opportunities for future work related to the collecting of information concerning the count and ratings of downloaded materials and their analysis by subjects, authors, keywords, type, etc. with means of tools for data processing, analysis and mining [16]. Similar analysis could assist to improve the quality of the materials in a way that they have to be useful, as well as to arouse an interest.

\section{REFERENCES}

[1] J. C. Nordbotten, "Multimedia information retrieval systems", 2008, available at: http://nordbotten.com/ADM/ADM_book/MIRS-frame.htm (accessed 17 February 2015). 
[2] Technical school of Electronic Systems to Technical University, Sofia, "Software training in Technical school of Electronic Systems to Technical University: Lectures and other materials on software specialties", 2004-2015, available at: http://lubo.elsys-bg.org (accessed 17 February 2015).

[3] High School "Raycho Karolev", Gabrovo, "Electronic library", 2013, available at: http://rk-biblioteka.zymichost.com (accessed 17 February 2015).

[4] M. Musa, "Electronic teaching materials: Lessons and exercises on informatics and information technologies", High School "Father Paisii", Kardzhali, 2007, available at: http://www.paisiikardjali.com/uroci/index.php (accessed 17 February 2015).

[5] High School "Nayden Gerov", Lom, "Electronic teaching materials: Tasks in Nayden Gerov", 2010-2015, available at: http://zadachi.gymnasium-lom.com (accessed 17 February 2015).

[6] High School "Dimitar Blagoev", Provadia, "Electronic teaching materials: Resources on informatics and information technologies", 2007, available at: http://www.it.souprovadia.info/?q=node (accessed 17 February 2015).

[7] D. Pechenyashki, "Electronic teaching materials on informatics and computer architectures", High School of Economics, Veliko Tarnovo, 2006, available at: http://www.iit.net-bg.info/inf.html (accessed 17 February 2015).

[8] D. Martynova, "Electronic teaching materials related to informatics and information technologies", Language School "Prof. Dr. Assen Zlatarov", Veliko Tarnovo, 2014, available at: http://egvt.alle.bg (accessed 17 February 2015)
[9] M. Bankova, "Electronic teaching materials on informatics and information technologies", Professional High School of Electrical Engineering, Varna, 2015, available at: http://bankova.ucoz.com (accessed 17 February 2015).

[10] Z. Zhekova, "Electronic teaching materials on informatics and information technologies", High School with teaching foreign languages "A. S. Pushkin", Varna, 2005, available at: http://jemil.my.contact.bg/it.htm (accessed 17 February 2015).

[11] H. Garcia-Molina, J. D. Ullman, and J. Widom, Database Systems: The Complete Book, Williams, 2002.

[12] A. M. Langer, Analysis and Design of Information Systems, Springer, 2008.

[13] T. M. Connolly and C. E. Begg, Database systems: a practical approach to design, implementation, and management, Addison-Wesley, 2005.

[14] P. Chen,"The Entity-Relationship Model: Toward a Unified View of Data", ACM Transactions on Database Systems, Vol.1, No.1, 1976, pp. 9-36.

[15] N. Nenkov and I. Ibryam, "Incentives and motives for studying Hadoop, HBase, MongoDB, Cassandra, NoSQL in subject Databases and Applications of college specialty Informatics and Information Technologies", In Proceedings of Mathematics, Computer Science and Computer information technologies, vol. 1, University Publishing House "K. Preslavski", 2012, pp. 398- 401 (in Bulgarian).

[16] N. Nenkov and I. Ibryam, "A survey of the open source platforms Rapidminer and Konstanz Information Miner (KNIME) for data processing, analysis and mining", In Proceedings of Pedagogical College, Dobrich, vol. 6, University Publishing House "K. Preslavski", 2013, pp. 124-129 (in Bulgarian). 